\title{
Constant-Frequency Multi-Resonant Converter-Fed DC Motor Drives
}

\author{
K.T. Chau, T.W. Ching and C.C. Chan \\ The University of Hong Kong
}

\begin{abstract}
Low-inductance de motors with high power density and low rotor inertia are becoming more attractive, particularly for servo applications. In order to maintain their current ripples within acceptable levels, power converters need to operate at high switching frequencies. However, the increase in switching frequencies realizable by hard-switching techniques accompanies the increase in switching losses and switching stresses. In this paper, recent soft-switching dc-dc converters are discussed for application to de motor drives. The most feasible one, namely the zero-voltage-switching (ZVS) constantfrequency multi-resonant converter (CF-MRC), has been identified to be appropriate for de motor drives. This softswitching converter not only possesses the advantages of achieving high switching frequencies with practically zero switching losses and eliminating variable-frequency operation, but also provides full ranges of voltage conversion and load variation. A ZVS-CF-MRC-fed dc motor drive has been prototyped and tested. Experimental results verify the successful application of the ZVS-CF-MRC to dc motor drives, which takes definite advantages of high efficiency, small current ripples and minimum switching stresses.
\end{abstract}

\section{INTRODUCTION}

With the recent advances in high-performance motor designs for high-power-density applications, the lowinductance motor is becoming more attractive [1]. This motor has a number of advantages such as higher power density, lower rotor inertia, smoother commutation and lower manufacturing costs. However, as the corresponding motor inductance is reduced dramatically by several hundredfolds, from tens of millihenry to hundreds of microhenry, it suffers from high current ripples, resulting in increased losses and switching stresses.

The simplest way to alleviate this problem is to add a choke in series with the motor to limit these current ripples within acceptable values. But, this measure usually involves a bulky choke which in effect degrades the benefits associated with the low-inductance motor design. The more viable solution is to significantly increase the switching frequency of power converters from less than one to over one hundred kilohertz. However, with available power devices technologies, hard-switching or so-called conventional pulsewidth-modulation (PWM) converters are deemed optimal to operate at tens of kilohertz. By switching at higher frequencies to suppress the current ripples, these converters impose high switching losses and switching stresses.
In the area of switched-mode power supplies (SMPS), there has been an ever increasing demand to increase the switching frequency to allow the use of smaller filters and energy-storage elements, thus providing higher power density and better dynamic performance. Within this decade, numerous soft-switching converters have been successfully developed to allow power devices in SMPS operating at favorable conditions, leading to achieve high power density and high efficiency [2].

Recently, soft-switching techniques have also been developed for power converters of motor drives. However, the development has been heavily biased on soft-switching inverters for ac motor drives [3]. The soft-switching converters for dc motor drives have been either overlooked or assumed that those being developed for SMPS can be directly applicable [4]. To the best of the authors' knowledge, neither feasibility studies nor evaluations of softswitching converters for dc motor drives have been discussed in industrial electronics literatures. It is the purpose of this paper to launch the discussion on soft-switching converters for application to dc motor drives. Based on their operating principles and performance characteristics, the most feasible one is proposed, designed and then tested for applying to a dc motor drive.

\section{SOFT-SWITCHING CONVERTERS}

Soft-switching converters, being developed for SMPS, are generally classified as the resonant converter (RC), quasiresonant converter (QRC), quasi-squarewave converter (QSC), multi-resonant converter (MRC) and zero transition converter (ZTC) [5]. Except the ZTC which inherently operates at constant switching frequency, the others originally operate at variable switching frequency and have recently been extended to constant-frequency versions, socalled the CF-RC, CF-QRC, CF-QSC and CF-MRC. Constant-frequency operation takes definite advantages over variable-frequency one because it favors the optimization of reactive components and closed-loop bandwidth as well as the filtering of EMI and noise. Instead of using variablefrequency modulation, the control of CF converters is generally accomplished by means of PWM.

The common feature of these soft-switching converters is the existence of a resonant tank or network which is used to shape the current and voltage waveforms of power devices to achieve either zero-voltage-switching (ZVS) or zero-current- 
switching (ZCS). Since power MOSFET is the most suitable power device for high-frequency low-power applications such as low-inductance dc servos, ZVS is usually preferred to ZCS because it can eliminate the major switching losses due to the discharging of its inherent junction capacitance.

At present, those ZVS-CF versions of soft-switching converters include the ZVS-CF-RC, ZVS-CF-QRC (sometimes called ZVS-PWM converter), ZVS-CF-QSC, ZVS-CF-MRC and ZVS-ZTC (usually called ZVT-PWM converter) [5]-[11]. Focusing on those single-ended converter types to minimize the hardware count and control complexity, the ZVS-CF-RC will not be considered because it usually requires a full-bridge topology, whereas the others are shown in Fig. 1.

The ZVS-CF-QRC is converted from the conventional ZVS-QRC by adding an auxiliary switch across the rectifier diode or across the resonant inductor [6]-[8]. Its major advantages and disadvantages are as follows:

() ZVS-CF operation for both switches.

(-) Wide load range.

().) Low current stress.

(2) Narrow voltage conversion range.

(2) High voltage stress.

The ZVS-CF-QSC is similarly converted from its frequency-modulated counterpart [6]. Its major features are listed below:

(-) ZVS-CF operation for both switches.

(). Low voltage stress.

$\otimes$ Limited voltage conversion and load ranges.

(2) High current stress.

Similar to the ZVS-CF-QRC, the ZVS-CF-MRC is converted from the conventional ZVS-MRC [6],[9]. The major advantages and disadvantages are as follows:

(:) ZVS-CF operation for both switches.

(3) Complete voltage conversion range (from zero to unity).

(3) Complete load range (from no load to full load).

(-) Capable of short-circuit operation.

(-) Absorb all major parasitics for high-frequency operation.

(2) Moderate voltage and current stresses.

Instead of using a series resonant network, the ZVTPWM converter employs an auxiliary shunt network to achieve ZVS [10],[11]. Its major features are below:

() ZVS-CF operation for the main switch.

(-) Low voltage and current stresses.

(-) Wide load and line ranges.

(2) Limited voltage conversion range.

(2) Hard-switching for the auxiliary switch.

Based on the above merits and demerits, the ZVT-PWM converter has been deemed most desirable for applications to SMPS because of minimum voltage and current stresses as well as wide load and line ranges. Its limitation in the voltage conversion range does not significantly affect the output voltage regulation with fluctuation in the line voltage, while the hard-switching losses in the low-power auxiliary switch can be acceptable. However, the major criteria of softswitching converters for dc motor drives are different to those for SMPS and are listed below:

- Full voltage conversion and load ranges are essential.

- Capability of short-circuit operation is preferable.

- Minimum voltage and current stresses are preferable.

- Minimum hardware and simple control are preferable.

Therefore, even in the presence of moderate voltage and current stresses, the ZVS-CF-MRC possesses the unique advantages of full conversion and load ranges, leading to be the most feasible soft-switching converter for application to dc motor drives.

\section{ZVS-CF-MRC OPERATION}

Fig. 2 shows the ZVS-CF-MRC-fed dc motor drive in which the armature winding of the motor provides the function of the filter inductor as used in SPMS. Detailed theoretical derivations of the ZVS-CF-MRC are omitted here to facilitate the readability whereas the operating principle and performance characteristics are provided.

Basically, the ZVS CF-MRC possesses four topological stages within a switching cycle as shown in Fig. 3:

- T1: $S W_{1}$ or $D_{S}$ on, $S W_{2}$ and $D$ off.

- T2: $S W_{1}$ and $D_{S}$ off, $S W_{2}$ and $D$ off.

- T3: $S W_{1}$ and $D_{S}$ off, $S W_{2}$ or $D$ on.

- T4: $S W_{1}$ or $D_{S}$ on, $S W_{2}$ or $D$ on.

Also, $T l$ can be split into two substages, namely the turn-on of $S W_{l}$ denoted as $T I_{A}$, and the turn-on of $D_{S}$ as $T I_{B}$. The normalized duration between the turn-offs of $S W_{1}$ and $S W_{2}$ with respect to the switching period $T_{s}$ is defined as the control variable $\delta$, so-called the duty cycle. The sequence of these topological stages determines the mode of operation. There are four possible operating modes shown in Fig. 4, namely modes $1,2,3$ and 4 . The corresponding typical waveforms of these four modes of operation are depicted in Fig. 5. As far as external properties are concerned, it is convenient to treat operation in modes 1,2 and 3 as if the converter operates in a single mode. Among them, modes 1 and 2 operate at different loads and with positive $\delta$, whereas mode 3 with negative $\delta$ for all loads. Mode 4 is less practical because its operating region is restricted.

The combined characteristics of voltage conversion $\mu$ (ratio of output dc voltage to input dc voltage) versus the duty cycle $\delta$ with different normalized load current $\lambda$ is shown in Fig. 6 whereas $\mu$ versus $\lambda$ with different $\delta$ is in Fig. 7 , in which the normalized switching frequency with respect to the resonant frequency is selected as 0.9 and $C_{S}$ is the same as $C_{D}$. Hence, it can be seen that the ZVS-CF-MRC possesses the distinct advantages of complete voltage conversion and load ranges. 

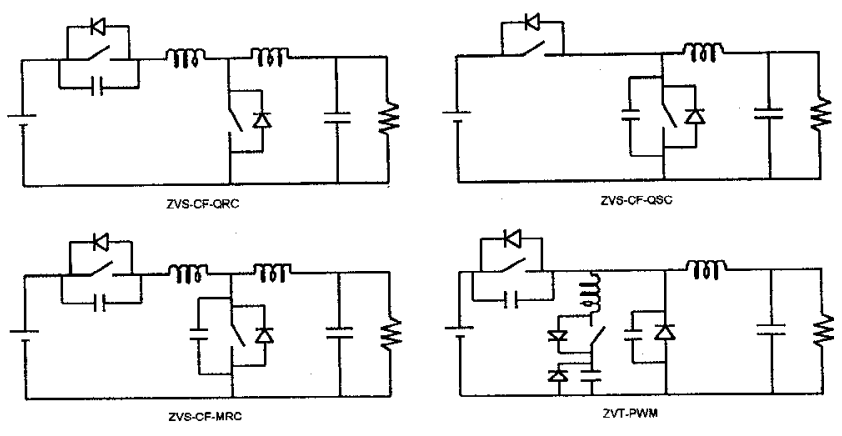

Fig. 1 ZVS-CF soft-switching buck converters

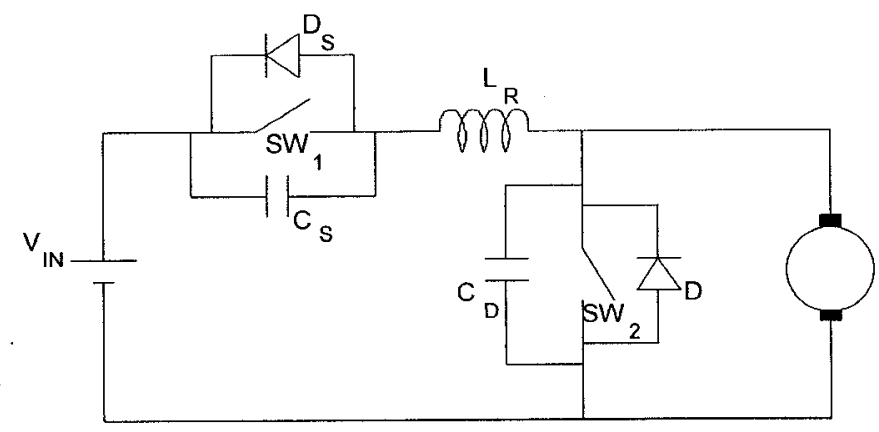

Fig. 2 ZVS-CF-MRC-fed dc motor drive

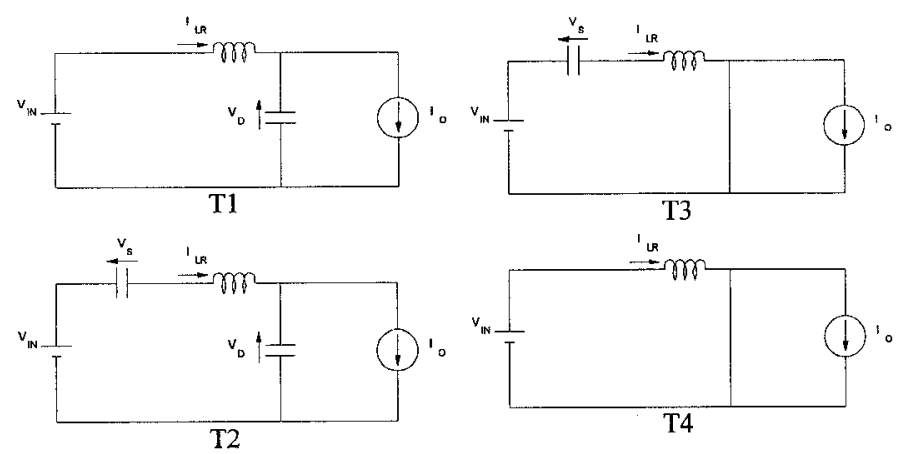

Fig. 3 Four topological stages

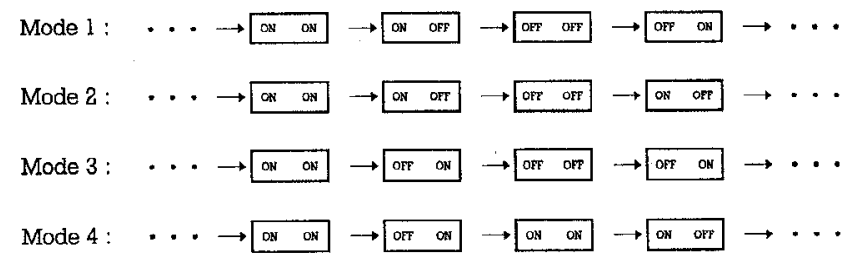

Now : :

Fig. 4 Four operating modes

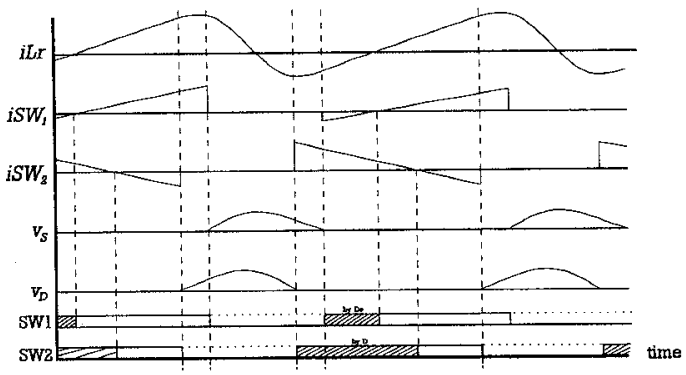

Mode 1

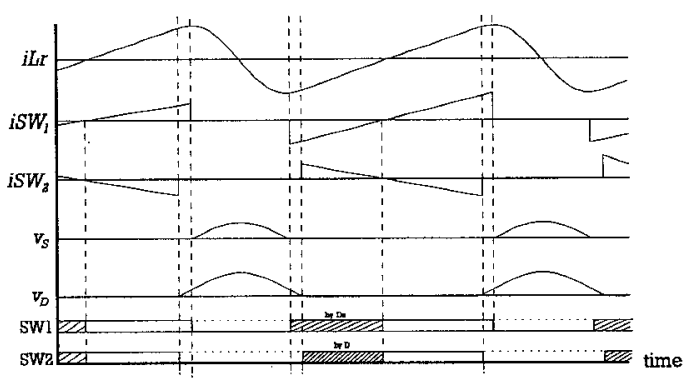

Mode 2

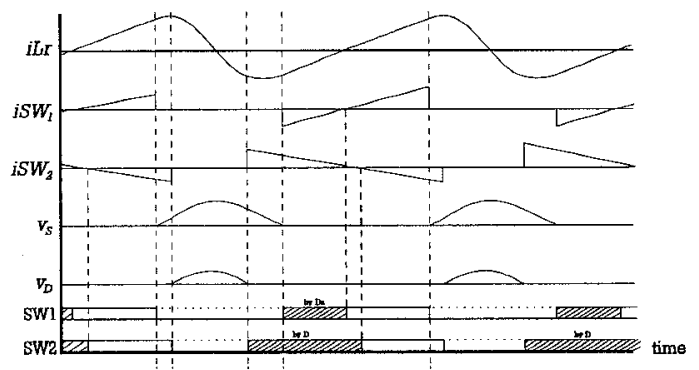

Mode 3

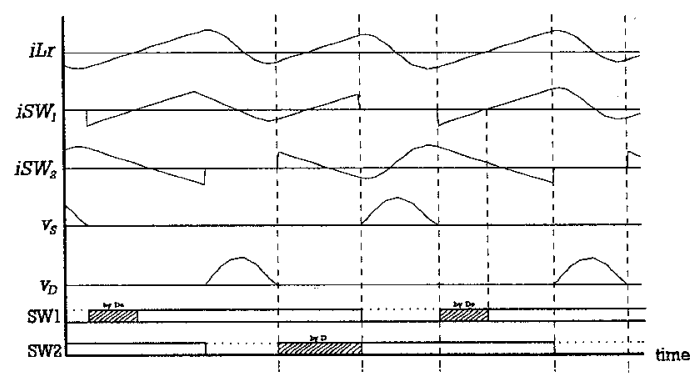

Mode 4

Fig. 5 Typical waveforms of four modes of operation 


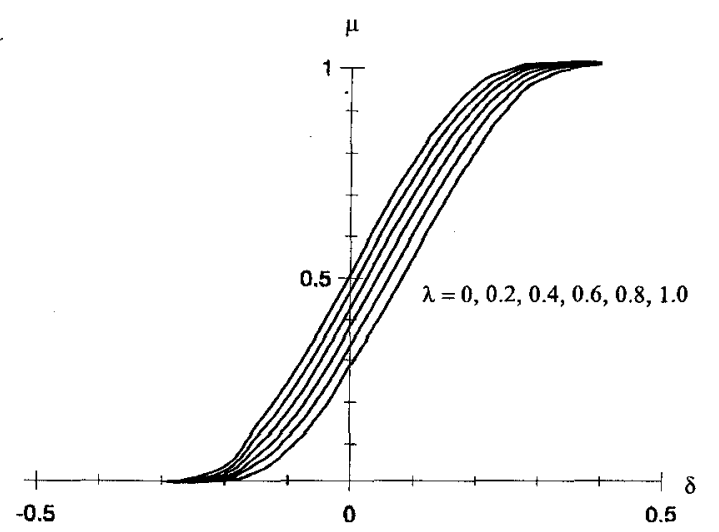

Fig. 6 Voltage conversion versus duty cycle

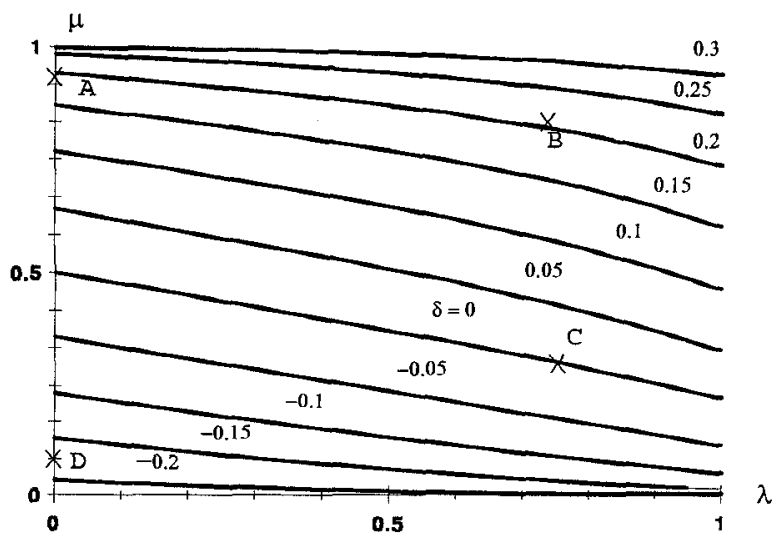

Fig. 7 Voltage conversion versus load

\section{DESIGN CONSIDERATIONS}

The design specification of the ZVS-CF-MRC for a dc motor is as follows:

- Input voltage $V_{I N}: 110 \mathrm{~V}$.

- Output voltage $V_{0}: 0-110 \mathrm{~V}$.

- Load current $I_{o}: 0-1.4 \mathrm{~A}$.

The switching frequency is selected as $150 \mathrm{kHz}$. Based on the voltage conversion characteristics shown in Fig. 7 for $f=0.9$ and $C_{D} / C_{S}=1$, the resonant frequency can be calculated as $f_{r}=167 \mathrm{kHz}$. The maximum normalized load $I_{n(\max )}$ for $f=0.9$ and $C_{D} / C_{S}=1$ is 1.3 , and the characteristic impedance $Z_{o}$ is chosen such that $I_{o(\max )}$ lies within the operating region. Hence, it can be deduced that $Z_{0}<92 \Omega$. By selecting $Z_{o}=90 \Omega$, the resonant inductor and resonant capacitors can then be calculated as $L_{R}=85.6 \mu \mathrm{H}$ and $C_{S}=$ $C_{D}=0.01 \mu \mathrm{F}$.

Fig. 8 illustrates the circuit diagram of the controller and driver for the ZVS-CF-MRC, where $V R I-8$ are of $500 \mathrm{k} \Omega, R_{x}$ are of $1 \mathrm{k} \Omega, R_{y}$ are of $470 \Omega$, and $C_{x}, C_{y}$ and $C_{f}$ are of $100 \mathrm{pF}$. The TL494 is a fixed-frequency PWM IC, incorporating the primary building blocks required for the control of the converter. Its internal linear sawtooth oscillator is frequencyprogrammable by external components, $V R 6$ and $C_{f}$. Input is fed via $V R I$ and is compared with the setting $V R 3$ by the comparator. VR4 and VRS are used to set the maximum and minimum duty cycles of the modulated signal, respectively. The modulated signal from pins 9 and 10 of TL494 is fed to a monostable multivibrator 74LS123. VR7, $R_{x}$ and $C_{x}$ are used to determine the delay between the outputs 1 and 2. The output 1 is the controlled PWM output, while the output 2 is with a constant duty cycle determined by $V R 8, R_{x}$ and $C_{y}$. Both the output signals are fed to their individual optocoupler 6 N137 and MOS-driver DS0026. The DS0026 works as an interface circuit to drive the power MOSFET from TTL signal, and can provide high current and voltage levels necessary to drive large capacitive loads at high speeds. Since the output of the MOS-driver is of totem-pole type, no external component is required to be connected between the MOSFET and DS0026.

\section{EXPERIMENTAL RESULTS}

In order to verify this work, a ZVS-CF-MRC-fed dc motor drive is prototyped. The active switch $S W_{l}$ and passive switch $D_{S}$ can be implemented using the power MOSFET IXFH26N50 which possesses an internal anti-parallel connected diode. Similarly, another $L X F H 26 N 50$ is used for $S W_{2}$ and $D$. The capacitors $C_{S}$ and $C_{D}$ are selected as $0.01 \mu \mathrm{F}$, and should be of polypropylene to allow for high-frequency resonance. The inductor $L_{R}$ is of $85.6 \mu \mathrm{H}$.

As shown in Fig. 9, the operating efficiency $\eta$ of the ZVSCF-MRC is plotted against the voltage conversion $\mu$ with different loading current $\lambda$ of the $\mathrm{dc}$ motor. As expected, the efficiency is high for the major operating range, especially at high loads, whereas it is relatively low for low-speed range where the output voltage is low. This low-voltage output makes the converter operating in mode 3 in which the conduction time of $S W_{2}$ or $D$ is lengthened, leading to increase the conduction losses.

Fig. 10 shows some typical experimental waveforms. The corresponding operating points are marked with ' $x$ ' in Fig. 7 to illustrate its outstanding ranges of voltage conversion and load, which represent the following conditions:

- A: Mode 1 operation at high load.

- B: Mode 2 operation at no load.

- C: Mode $1 / 3$ boundary operation at high load.

- D: Mode 3 operation at no load.

It can be found that these experimental waveforms agree well with the theoretical waveforms. Moreover, it has been tested that both power switches can maintain ZVS-CF operation for different voltage conversions and loads, including high-voltage high-current, high-voltage low-current, low-voltage high current, low-voltage low-current, no-load (open-circuit) and locked-rotor (short-circuit) conditions. 


\section{CONCLUSION}

In order to maintain the current ripples of low-inductance dc motors within acceptable levels, the power converter needs to operate over $100-\mathrm{kHz}$ switching frequencies. Conventional hard-switching PWM converters suffer from high switching losses and switching stresses.

In this paper, recent soft-switching dc-dc converters are evaluated for applications to dc motor drives. The most feasible one has been identified to be the ZVS-CF-MRC. This converter not only possesses the advantages of achieving high switching frequencies with practically zero switching losses and eliminating variable-frequency operation, but also provides full ranges of voltage conversion and load variation. Since it behaves as a constant current source after reaching the maximum output current while its maximum and minimum duty cycles are internally limited by the settings of VR4 and VR5, the converter can handle both no-load and short-circuit conditions without any additional protective measures.

This ZVS-CF-MRC-fed dc motor drive takes definite advantages over the PWM converter-fed dc motor drive such as the dramatic reduction in current ripples and significant improvement in efficiency. It should be noted that although most soft-switching converters may suffer from the trade-off between the reduction in switching losses and the increase in conduction losses, the experimental results verify that the use of the ZVS-CF-MRC for dc motor drives can provide a high efficiency over the major operating range.

For high-power dc motor drives, the minority carrier power devices such as IGBTs and MCTs are needed. Thus, the ZCS counterpart is deemed to be preferable. Although this ZCS-CF-MRC has not been mentioned in this paper, its operating principle is quite similar and can be easily derived by applying circuit duality.

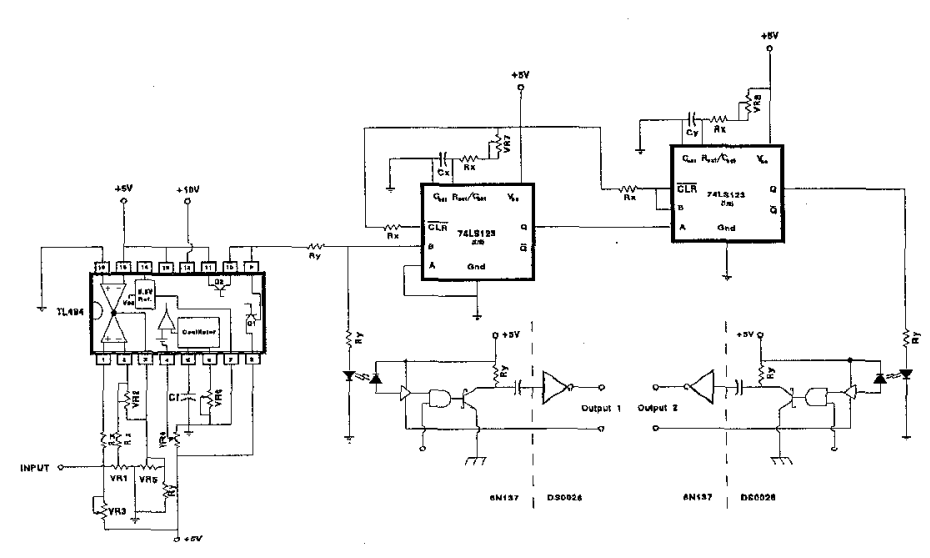

Fig. 8 Controller and driver

\section{REFERENCES}

[1] G. Venkataramanan, "Evaluation of inverter topology options for low inductance motors," Proc. IEEE IAS, 1993, pp. 1041-1047.

[2] G. Hua, and F.C. Lee, "Soft-switching techniques in PWM converters," IEEE Trans. Ind. Electron., vol. 42, 1995, pp. 595-603.

[3] J.S. Lai, R.W. Young, Sr., G.W. Ott, Jr., and D. Chen, "A novel resonant snubber based soft-switching inverter," Proc. IEEE APEC, 1996, pp. 797-803.

[4] C.C. Chong, C.Y. Chan, and C.F. Foo, "A quasi-resonant converter-fed dc drive system," Proc. EPE, 1993, pp. 372377.

[5] M.M. Jovanovic, "Resonant, quasi-resonant, multiresonant and soft-switching techniques - merits and limitations," J Electron., vol. 77, 1994, pp. 537-554.

[6] D. Maksimovic and S. Cuk, "Constant-frequency control of quasi-resonant converters," IEEE Trans. Power Electron., vol. 6, 1991, pp. 141-150.

[7] G. Hua, and F.C. Lee, "A new class of zero-voltageswitched PWM converters," Proc. VPEC, 1991, pp.143150.

[8] C.C. Chan and K.T. Chau, "A new zero-voltage-switching dc/dc boost converter," IEEE Trans. Aero. Electron. Syst., vol. 29, 1993, pp. 125-134.

[9] K.T. Chau, "A new class of pulsewidth-modulated multiresonant converters using resonant inductor freewheeling," J Electron., vol. 77, 1994, pp. 703-714.

[10] G. Hua, C.S. Leu, and F.C. Lee, "Novel zero-voltagetransition PWM converters," Proc. VPEC, 1991, pp. 8188.

[11] G. Hua, C.S. Leu, Y. Jiang and F.C. Lee, "Novel zerovoltage-transition PWM converters," IEEE Trans. Power Electron., vol. 9, 1994, pp. 213-219.

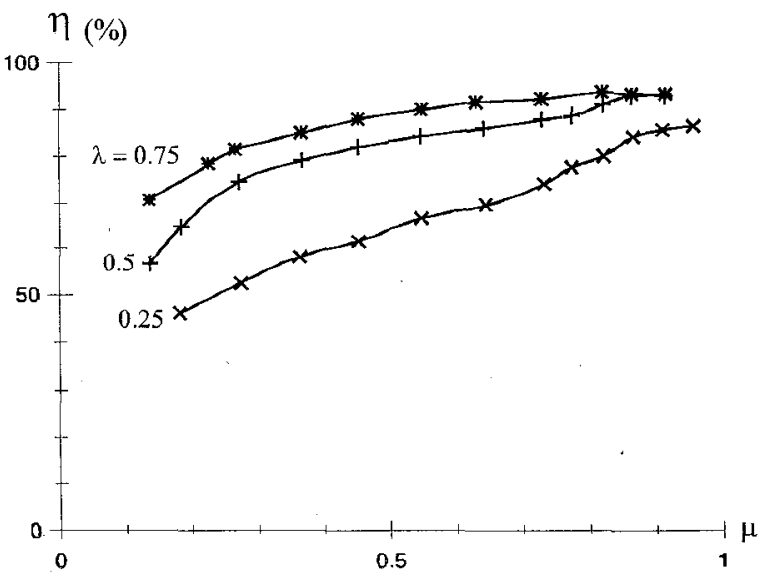

Fig. 9 Efficiency profiles 


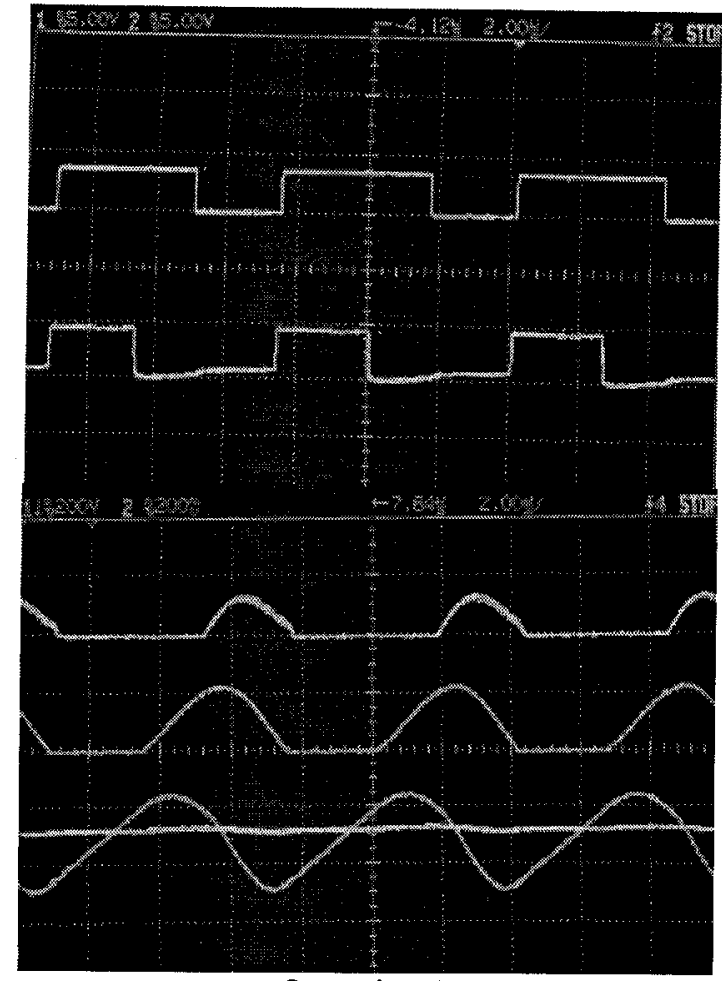

Operation A

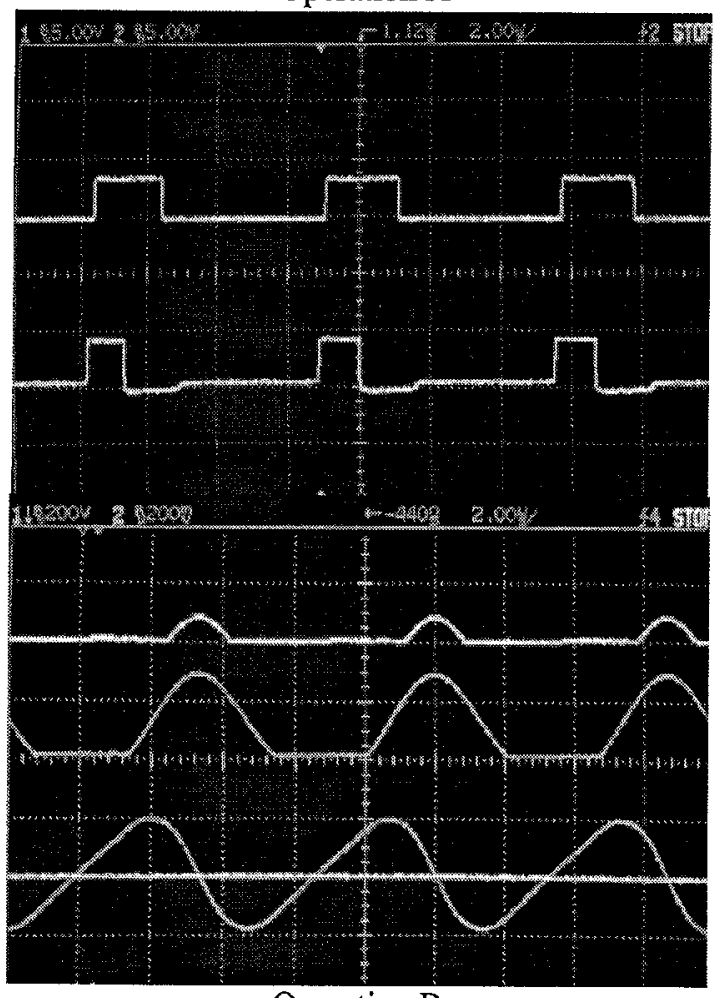

Operation B

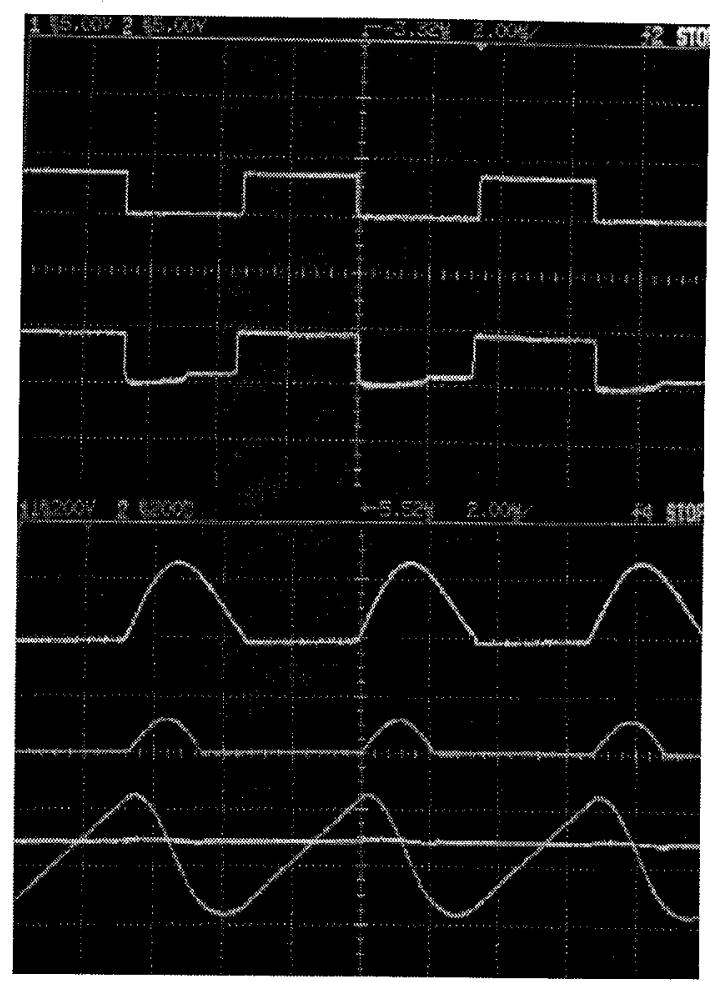

Operation C

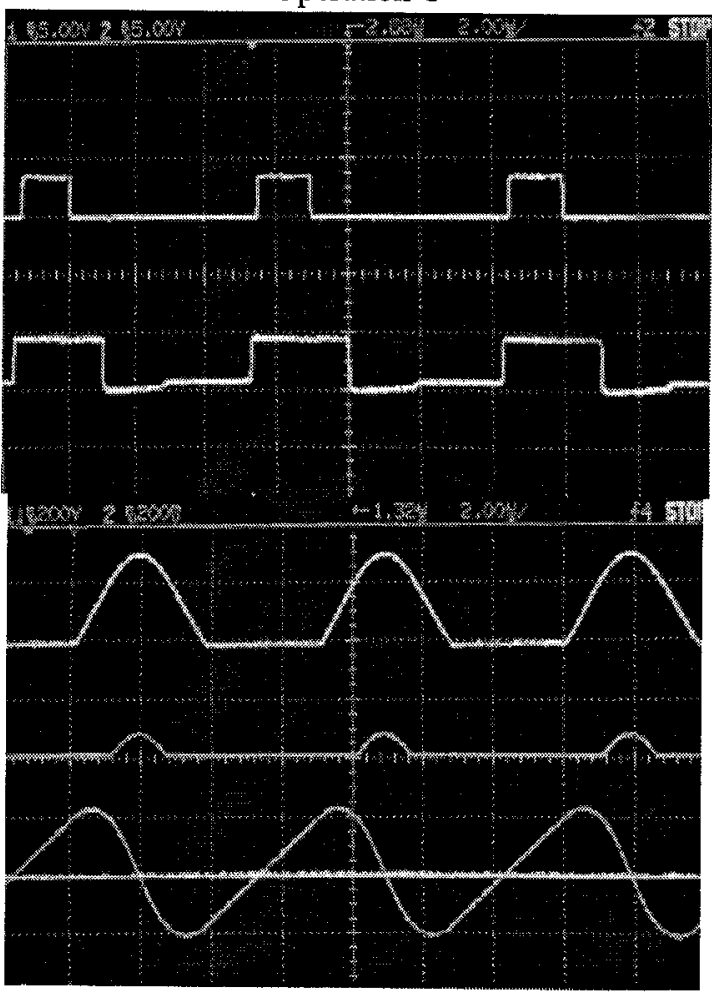

Operation D

Fig. 10 Experimental waveforms: SW1, SW2, (5 V/div); $\mathrm{V}_{\mathrm{S}}, \mathrm{V}_{\mathrm{D}},(200 \mathrm{~V} / \mathrm{div}) ; \mathrm{I}_{\mathrm{LR}}, \mathrm{I}_{\mathrm{O}},(2 \mathrm{~A} /$ div $)$ 